\title{
OPTIMAL CONVEX COMBINATIONS BOUNDS OF CENTROIDAL AND HARMONIC MEANS FOR WEIGHTED GEOMETRIC MEAN OF LOGARITHMIC AND IDENTRIC MEANS
}

\section{LADISLAV MATEJÍ́̌KA}

Abstract. In this paper, optimal convex combination bounds of centroidal and harmonic means for weighted geometric mean of logarithmic and identric means are proved. We find the greatest value $\lambda(\alpha)$ and the least value $\Delta(\alpha)$ for each $\alpha \in(0,1)$ such that the double inequality:

$$
\lambda C(a, b)+(1-\lambda) H(a, b)<L^{\alpha}(a, b) I^{1-\alpha}(a, b)<\Delta C(a, b)+(1-\Delta) H(a, b)
$$

holds for all $a, b>0$ with $a \neq b$. Here, $C(a, b), H(a, b), L(a, b)$ and $I(a, b)$ denote centroidal, harmonic, logarithmic and identric means of two positive numbers $a$ and $b$, respectively.

Mathematics subject classification (2010): 26 D15.

Keywords and phrases: Convex combinations bounds, centroidal mean, harmonic mean, weighted geometric mean, logarithmic mean, identric mean.

\section{REFERENCES}

[1] H. Alzer And S. L. QiU, Inequalities for means in two variables, Arch. Math. (Basel) 80, 2 (2003), 201-215.

[2] P. S. Bullen, D. S. Mitrinovič And P. M. VAsič, Means and their inequalities, D. Reidel Publishing Co., Dordrecht, 1958.

[3] B. C. CARlson, The logarithmic mean, Amer. Math. Monthly 79 (1972), 615-618.

[4] Y. H. ChU, S. W. Hou AND W.F. XIA, Optimal convex combinations bounds of centroidal and harmonic means for logarithmic and identric means, Buletin of the Iranian Mathematical Society, Vol. 39 No. 2 (2013), 259-269.

[5] P. Kahling AND J. Matkows Ki, Functional equations involving the logarithmic mean, Z. Angew Math. Mech. 76, 7 (1996), 385-390.

[6] L. MAtejÍČKA, Proof of One Optimal Inequalities for Generalized Logarithmic, Arithmetic and Geometric Means, J. Inequal. Appl., Article ID 902432, 5 pages.

[7] A.O. Pitinger, The logarithmic mean in n variables, Amer. Math. Monthly 92, 2 (1985), 99-104.

[8] G. Pólya AND G. SzEGő, Isoperimetric inequalities in mathematical physics, Princeton University Press, Princeton, 1951.

[9] W. Seiffert, Problem 887, Nieuw Archief voor Wiskunde, Vol. 11, No. 2, 176-176.

[10] J. VAVRo, M. KoPECKÝ AND J. VAVRo JR., Nové metódy a prostriedky riešenia sústav telies, (2007)

[11] Gao Shaoqin, Gao Hongya, Shi Wenying, Optimal convex combination bounds of the centroidal and harmonic means for the seiffert mean, International Journal of Pure and Applied Mathematics 70, 5 (2011), 701-709.

[12] ZHEN-HANG YANG, New sharp bounds for logarithmic mean and identric mean, Journal of Inequalities and Applications (2013), 116. 